\title{
Structure of Phase III and Polymorphism of $\left(\mathrm{CH}_{3}\right)_{3} \mathrm{CBr}$
}

\author{
Philippe Negrier, ${ }^{\dagger}$ María Barrio, ${ }^{\star}$ Josep Ll. Tamarit,,$*$ Nestor Veglio, ${ }^{\star}$ and \\ Denise Mondieig ${ }^{\dagger}$ \\ †entre de Physique Moléculaire, Optique et Hertzienne, UMR 5798 au CNRS Université Bordeaux I, \\ 351 , cours de la Libération, 33405 Talence Cedex, France, and ${ }^{\star}$ Grup de Caracterització de Materials, \\ Department de Física i Enginyeria Nuclear, ETSEIB, Diagonal 647, Universitat Politècnica de \\ Catalunya, 08028 Barcelona, Catalonia, Spain
}

\begin{abstract}
The polymorphism of 2-bromo-2-methyl-propane $\left(\left(\mathrm{CH}_{3}\right)_{3} \mathrm{CBr}\right)$ has been investigated by both thermal and $\mathrm{X}$-ray powder diffraction experiments. The long time unknown structure of the low-temperature phase III has been determined by X-ray powder diffraction as orthorhombic Pmn $2_{1}$, with lattice parameters $a=19.1350(4) \AA, b=5.7378(1) \AA$, and $c=$ $10.9626(2) \AA$ at $180 \mathrm{~K}, Z=8$ and with an asymmetric unit containing one molecule in a general position and two additional molecules placed in a mirror $\left(Z^{\prime}=1+1 / 2+1 / 2\right)$. The phase transitions between the different phases have been characterized at normal pressure as well as at high pressures (up to $300 \mathrm{MPa}$ ). From the $p \quad T$ slopes of the two-phase coexistence lines and density measurements as a function of pressure, the volume variations at the transition points have been obtained and compared with those obtained by means of X-ray powder diffraction at normal pressure. The packing as well as the anisotropy of the intermolecular interactions have been analyzed by means of the thermal-expansion tensor and compared with tert-butyl $\left(\left(\mathrm{CH}_{3}\right)_{3} \mathrm{CX}, \mathrm{X}=\mathrm{Cl}, \mathrm{CN}\right)$ related compounds.
\end{abstract}

\section{Introduction}

For molecular crystals, the transition from a complete orientational and translational disorder (isotropic liquid phase) toward complete order may be achieved in several stages in such a way that each phase transition involves a stepwise reduction of the disorder. Depending on whether orientational or translational orders appear when cooling the isotropic liquid, one is dealing with liquid crystals or plastic crystals, respectively. ${ }^{1,2}$ While the former are generally found in molecular materials formed by elongated molecules, plastic crystals are formed by substances whose molecular shapes are symmetrical about one or more axes and, particularly, those where the molecular shape is somewhat globular. Well-known examples of such molecular materials representative of plastic crystals (i.e., displaying orientationally disordered, OD, phases) are the tert-butyl compounds, $\left(\mathrm{CH}_{3}\right)_{3} \mathrm{CX}, \mathrm{X}=\mathrm{Cl}$, $\mathrm{Br}, \mathrm{NO}_{2}, \mathrm{CN}, \mathrm{SH}, \mathrm{COOH} \ldots$, because they have molecular shapes sufficiently close to spherical (due to the comparable size of the $\mathrm{X}$ groups to the methyl group) to enable orientational disorder in the solid state. ${ }^{3} 6$

Such compounds display a rich polymorphism that has stimulated a large number of experimental investigations as well as theoretical studies in order to rationalize the thermodynamic properties and molecular dynamics of the various solid phases. ${ }^{3}{ }^{23}$ Polymorphism may be defined as the ability of a compound to exist in different crystalline forms in which the molecules have different arrangements (packing) in the crystal lattice. ${ }^{24}$ Although the space group of the crystal lattice should be equal to or higher than that of the molecular pointgroup symmetry, nature overcomes such a restriction by forcing molecular reorientations along different axes, and thus making an inseparable link between crystal structure

*To whom correspondence should be addressed. E-mail: jose.luis.tamarit@ upc.edu. and dynamics which increases the complexity of finding the crystal assemblies. But even for fully ordered systems at the present state of the art, it is not possible to predict crystals structures reliably. ${ }^{25}{ }^{27}$ Examples of such a situation concern tert-butyl compounds $\left(\mathrm{CH}_{3}\right)_{3} \mathrm{CCl}$ (hereinafter referred to as $\mathrm{tBCl}$, IUPAC name: 2-chloro-2-methyl-propane) and $\left(\mathrm{CH}_{3}\right)_{3} \mathrm{CBr}$ (hereinafter referred to as tBBr, IUPAC name: 2-bromo-2-methyl-propane) for which the general van der Waals close packing should dominate the observed packing of the motifs. Although it might be assumed that owing to the large molecular symmetry similarities $\left(\mathrm{C}_{3 v}\right.$ symmetry $)$ of these two tert-butyl compounds they should form isostructural phases (and thus, a close polymorphism sequence), it was early shown that this circumstance is highly unlikely. ${ }^{3,8,16,17}$ Under their equilibrium vapor pressures, both compounds display three solid phases (I, II, and III in order of decreasing temperature). ${ }^{3,8,14,15,17,19,22,23}$ On cooling, the liquid phase of both compounds freeze into an orientationally disordered fcc (face-centered cubic) structure (phase I) with $Z=4$ (see Table 1 for temperatures). Upon further cooling, this phase transforms to a tetragonal $(\mathrm{P} 4 / \mathrm{nmm})$ phase for $\mathrm{tBCl}^{23}$ and to a rhombohedral phase for $\mathrm{tBBr} .^{3,28}$ Uniaxial molecular reorientations (3-fold rotations) about the $\mathrm{C}$-X axis $\left(C_{3}^{\prime}\right.$-axis or dipole axis of the molecule) and fluctuations of the dipole axis are present in both cases. ${ }^{5,11} 13,17$ Nevertheless, the fluctuations of the dipole axis are just a few degrees for $\mathrm{tBCl}$ while those for the rhombohedral phase of $\mathrm{tBBr}$ are really large (ca. $60^{\circ}$ ), giving to this phase II also the stamp of OD phase. ${ }^{5,29}$ Such characteristic comes up clearly by comparing the enthalpy change of the II I phase transitions, rather low for the case of $\mathrm{tBBr}$ (see Table 1). It is worth noting that the puzzle of experimental literature data concerning the symmetry of phase II of tBBr was recently solved by Rudman ${ }^{3}$ and lately confirmed. ${ }^{28}$ This phase was found to be isostructural to the stable OD phase of $\mathrm{CCl}_{4}$ and related halogenomethane compounds (as $\left(\mathrm{CH}_{3}\right)_{2} \mathrm{CCl}_{2},\left(\mathrm{CH}_{3}\right) \mathrm{CCl}_{3}, \mathrm{CCl}_{3} \mathrm{Br}$, 
Table 1. Temperature Transitions $T_{\mathrm{c}}$ and Entropy Changes $\Delta S$ Derived from Calorimetric Measurements at Normal Pressure, Slope of the Temperature Pressure Two Phase Equilibria $\mathrm{d} T_{\mathrm{c}} / \mathrm{d} p$ Derived from Thermal Analysis at High Pressure and Volume Changes Determined from the Clausius-Clapeyron Equation $\left(\Delta v^{\mathrm{CC}}\right)$, from X ray Powder Diffraction Measurements $\left(\Delta v^{\mathrm{XR}}\right)$ and from pvT Measurements $\left(\Delta v^{\mathrm{pvT}}\right)$ for the Different $\mathrm{Transitions}$ of $\left(\mathrm{CH}_{3}\right)_{3} \mathrm{CBr}$, Also at Normal Pressure ${ }^{a}$

\begin{tabular}{|c|c|c|c|c|c|c|c|}
\hline & $\begin{array}{l}T_{\mathrm{c}} \\
\mathrm{K}\end{array}$ & $\begin{array}{c}\Delta S \\
\mathrm{~J} \cdot \mathrm{K}^{1} \cdot \mathrm{mol}^{1}\end{array}$ & $\begin{array}{l}\left(\mathrm{d} T_{\mathrm{c}} / \mathrm{d} p\right) \\
\mathrm{K} \cdot \mathrm{MPa}\end{array}$ & $\begin{array}{c}\Delta v^{\mathrm{CC}} \\
\mathrm{cm}^{3} \cdot \mathrm{mol}^{1}\end{array}$ & $\begin{array}{c}\Delta v^{\mathrm{XR}} \\
\mathrm{cm}^{3} \cdot \mathrm{mol} \quad 1\end{array}$ & $\begin{array}{c}\Delta v^{\mathrm{pvT}} \\
\mathrm{cm}^{3} \cdot \mathrm{mol}\end{array}$ & ref \\
\hline \multirow[t]{4}{*}{ III-II } & $209.0 \pm 1.0$ & $28.23 \pm 0.80$ & $0.206 \pm 0.020$ & $5.81 \pm 0.73$ & $5.58 \pm 0.21$ & $5.50 \pm 0.71$ & this work \\
\hline & $209.3 \pm 0.5$ & $27.95 \pm 0.48$ & 0.174 & 4.86 & & & 43 \\
\hline & 208.0 & 27.15 & 0.20 & 5.43 & & & 44 \\
\hline & (183.6) & (11.3) & $(0.18)$ & (4.8) & & & 4,8 \\
\hline \multirow[t]{4}{*}{$\mathrm{II}-\mathrm{I}$} & $232.9 \pm 1.0$ & $4.12 \pm 0.15$ & $0.385 \pm 0.033$ & $1.59 \pm 0.19$ & $1.47 \pm 0.20$ & $1.50 \pm 0.10$ & this work \\
\hline & $231.8 \pm 0.3$ & $4.14 \pm 0.04$ & 0.368 & 1.54 & & & 43 \\
\hline & 233.0 & 4.49 & 0.40 & 1.80 & & & 44 \\
\hline & (219.8) & $(26.2)$ & $(0.17)$ & (4.4) & & & 4,8 \\
\hline \multirow[t]{2}{*}{ I L } & $254.9 \pm 1.1$ & $6.77 \pm 0.38$ & $0.512 \pm 0.020$ & $3.47 \pm 0.33$ & $4.02 \pm 0.19$ & $4.00 \pm 0.32$ & this work \\
\hline & $\begin{array}{c}255.5 \\
(247.8)\end{array}$ & $\begin{array}{c}7.69 \\
(7.65)\end{array}$ & $\begin{array}{c}0.51 \\
(0.57)\end{array}$ & $\begin{array}{l}3.93 \\
(4.6)\end{array}$ & & & $\begin{array}{l}44 \\
4,8\end{array}$ \\
\hline
\end{tabular}

${ }^{a}$ Values in parentheses correspond to $\mathrm{tBCl}$.

and $\left.\mathrm{CCl}_{2} \mathrm{Br}_{2}\right){ }^{28,30}{ }^{32}$ The evidence of the structural similarity and even the existence of an isomorphism relationship (the isostructural relationship being then included) between the $\mathrm{OD}$ phase II of $\mathrm{tBBr}$ and stable phase $\mathrm{I}$ of $\mathrm{CCl}_{4}$ was established throughout the existence of continuous mixed crystals for the whole concentration range. ${ }^{28}$ Even though the work of Rudman ${ }^{3}$ was based on single crystals grown from the liquid state into phase I and lately transformed to phase II without shattering, the disordered character of this phase II and the complexity ( $a=15.087(21) \AA, \alpha=89.17(7)^{\circ}$, and $Z=21$ ) made not possible a full structural determination, that is, to determine how many molecules are in the asymmetric unit and how this crystallographic asymmetric unit tessellates the space. The existence of an OD rhombohedral phase for $\mathrm{tBCl}$ was initially inferred at high-pressure by comparing the topological pressure temperature phase diagram to the experimental one and was recently confirmed. ${ }^{33}$

As far as the low-temperature phases of tert-butyl compounds are concerned, only the structures of $\mathrm{tBCl}^{8,23}$ and tertbutyl cyanide ${ }^{20}(\mathrm{X}=\mathrm{CN}$, hereinafter referred to as $\mathrm{tBCN})$ have been reported. Both structures are monoclinic, space group $P 2_{1} / m$ with $Z=2$ and one molecule per asymmetric unit $\left(Z^{\prime}=1\right)$. Lattice parameters are also very close $(a=$ 6.2491(9) $\AA, b=6.9346(11) \AA, c=6.408(16) \AA$ and $\beta=$ $94.38(2)^{\circ}$ for $\operatorname{tBCN}^{20}$ at $147 \mathrm{~K}$ and $a=6.2613(7) \AA, b=$ 7.5168(8) $\AA, c=6.0064(6) \AA$ and $\beta=92.124(8)^{\circ}$ for $\mathrm{tBCl}^{23}$ at 123.2 K or $a=6.2901(8) \AA, b=7.5315(9) \AA, c=6.0167(11) \AA$ and $\beta=92.09(2)^{\circ}$ at $\left.140 \mathrm{~K}^{8}\right)$. For tBBr, Bertie and Sunder ${ }^{18}$ in 1973 and Urban et al. ${ }^{22}$ in 1978 reported orthorhombic unit cells with relatively close parameters by indexing powder $\mathrm{X}$-ray diffraction patterns. Some years later Leadbetter et al. ${ }^{17}$ reported neutron scattering data for the three solid phases of $\mathrm{tBBr}$, but the authors wrote: “... because of the complexity of the powder pattern and the large number of molecules per unit cell in each phase (phases II and III) a full Rietveld profile refinement has not been possible." The last attempt to get the structure of phase III of $\mathrm{tBBr}$ was carried out by Rudman ${ }^{3}$ in 2001 . In spite of that he was able to grow single crystals for phase I and transform them to phase II; transition to phase III produced shattering.

The present experimental work was undertaken to attempt to complete the crystal structure of phase III and to reexamine the phase transitions of $\mathrm{tBBr}$ at normal pressure (i.e., in equilibrium with the vapor pressure) as well as at high(moderate) hydrostatic pressure (up to $300 \mathrm{MPa}$ ). As far as organic compounds are concerned, such a pressure range is high enough to unravel the polymorphism without noticeable intramolecular structural changes ${ }^{34}$ and to understand the pressure temperature polymorphism of simple compounds, one of the fundamental aspects in the physical chemistry field. ${ }^{35,36}$ A pressure temperature phase diagram as well as volume data as a function of pressure and temperature provide volume changes at the phase transitions and validate the lattice structures (usually obtained only at one temperature). Because previous attempts using single-crystal methods were not successful, low-temperature high-resolution X-ray powder diffraction was used. As we will prove, the claimed complexity of the phase III structure does not concern the "high" number of molecules in the unit cell, but the special motifs forming the asymmetric unit. It has been found that $Z^{\prime}=(1+1 / 2+1 / 2)$, with one molecule in a general position and two additional molecules placed in a mirror (then contributing as one-half each one). Thus, phase III of tBBr belongs to a reduced "selected group" (ca. 8\% according to the Cambridge Structural Database) for which $Z^{\prime}>1 .^{37}{ }^{42}$ But even more interesting is the fact that the molecular entity within the asymmetric unit is really simple, without different possible conformations and with a high molecular symmetry or, at the very least, no less than those of the tert-butyl compounds, $\left(\mathrm{CH}_{3}\right)_{3} \mathrm{CX}$.

The structural results as well as the thermodynamics of $\mathrm{tBBr}$ and $\mathrm{tBCl}$ and $\mathrm{tBCN}$ will be compared with each other.

In addition, the concomitant dynamical aspects (generally disregarded) of the polymorphism of these substances, largely explored, ${ }^{5}$ 7,11 14,17 will be rationalized as a function of the structures and the pressure volume temperature phase diagrams.

\section{Experimental Section}

tert Butyl bromide was supplied by Aldrich Chemical Co. (purity better than 98\%) and always handled under an $\mathrm{Ar}$ atmosphere without further purification.

2.1. High Resolution $X$ ray Powder Diffraction Measurements. High resolution $\mathrm{X}$ ray powder patterns were isothermically re corded by means of a horizontally mounted INEL cylindrical position sensitive detector (CPS120) ${ }^{45}$ equipped with a liquid nitro gen 600 series Cryostream Cooler from Oxford Cryosystems with a temperature accuracy of $0.1 \mathrm{~K}$ and similar for fluctuations.

The detector, used in Debye Scherrer geometry (transmission mode), consists of 4096 channels and enables a simultaneous recording of the diffraction profile over a $2 \theta$ range between 2 and $115^{\circ}$ (angular step of $0.029^{\circ}$ in $\left.2 \theta\right)$. Monochromatic $\mathrm{CuK} \alpha_{1}(\lambda=$ $1.54059 \AA)$ radiation was selected by means of an asymmetric focusing incident beam curved quartz monochromator. The gen erator power was set to $1.0 \mathrm{~kW}(40 \mathrm{kV}$ and $25 \mathrm{~mA})$. Peakoc 
application from Diffractinel software was used for the calibration and for the conversion channel angle after an external calibration using the cubic phase $\mathrm{Na}_{2} \mathrm{Ca}_{3} \mathrm{Al}_{2} \mathrm{~F}_{14}$ mixed with silver behenate. The conversion was done by means of cubic spline fittings in order to correct the deviation from angular linearity in position sensitive detector (PSD) according to recommendations. ${ }^{45}$

The standard measurements were performed at least every $10 \mathrm{~K}$ step in the temperature range of phase III, every $23 \mathrm{~K}$ for phase II, and every $5 \mathrm{~K}$ for the orientationally disordered phase I. Acquisition times were no less than $60 \mathrm{~min}$ for patterns. The slew rate was $1 \mathrm{~K} \cdot \min ^{1}$ with a stabilization time of $5 \mathrm{~min}$ at each temperature before data collection.

A longer time acquisition pattern of $2 \mathrm{~h}$ for phase III (at $180 \mathrm{~K}$ ) was measured for structure determination and refinement purposes.

The modules Powder Indexing (cell search), Powder Refinement (full profile determination after pseudo Voigt fittings ${ }^{46}$ ), and Pow der Solve ${ }^{47}$ of the Material Studio application ${ }^{48}$ have been used to resolve the crystal structure.

Liquid samples were sealed in Lindemann capillaries $(0.3 \mathrm{~mm}$ diameter), which rotated perpendicularly to the $\mathrm{X}$ ray beam during the experiment to improve averaging of the crystallites thus mini mizing preferential orientations.

2.2. Thermal Analysis. Thermal analysis measurements at normal pressure were conducted by means of a Q100 thermal analyzer from TA Instruments equipped with a RCS low temperature device. Heating and cooling rates of $2 \mathrm{~K} \cdot \min { }^{1}$ were used. Sample masses around $25 \mathrm{mg}$ were encapsulated into high pressure stainless steel pans with $\mathrm{Au}$ covers (from Perkin Elmer) to prevent possible reaction with the container.

The transition temperatures as a function of pressure (up to $300 \mathrm{MPa}$ ) were measured in a low temperature high pressure apparatus similar to that described elsewhere. ${ }^{49}$ The DTA traces were obtained on heating with scanning rates of about $1 \mathrm{~K} \cdot \min { }^{1}$. The measurements were performed in closed indium capsules containing about $40 \mathrm{mg}$ of the sample. The usual experimental error is $\pm 0.5 \mathrm{~K}$ for the temperature and $\pm 0.5 \mathrm{MPa}$ for the pressure values.

2.3. Density Measurements. Liquid density measurements at normal pressure were carried out from 278 to $353 \mathrm{~K}$ using an Anton Paar D5000 densimeter with temperature stability of $\pm 0.02 \mathrm{~K}$ and uncertainties in density of ca. $5 \times 10^{5} \mathrm{~g} \cdot \mathrm{cm}{ }^{3}$. The densimeter was calibrated with bidistilled water and $n$ hexane $(99.9 \%)$. The density values were taken from refs 50 and 51.

Density measurements as a function of pressure and temperature were performed by means of a homemade pvT device similar to that described in refs 9 and 52 .

The uncertainty of the density measurements is around $10^{4} \mathrm{~g} \cdot \mathrm{cm}^{3}$, while for temperature and pressure errors are similar to those of the thermal analyzer as a function of pressure.

\section{Results and Data Analysis}

3.1. Structure Determination of Phase III of $\mathrm{tBBr}$. In order to build up a rigid body molecule, the software Forcite from Materials Studio package together with the Compass forcefield was used. ${ }^{48}$ The minimization energy process converged to an almost perfect tetrahedral molecular symmetry $(\mathrm{C} \mathrm{Br}=$ $1.948 \AA ; \mathrm{C} C=1.533 \AA ; \mathrm{C} \quad H=1.102 \AA ; \mathrm{C} \quad \mathrm{C} \quad \mathrm{Br}=108.25^{\circ}$; H C $H=107.66^{\circ}$; C C $C=110.66^{\circ}$; C C $H=111.47^{\circ}$ ).

Potential solutions of the cell parameters and space groups were obtained using X-Cell software ${ }^{53}$ available in the module Powder Indexing of Material Studio.

The cell parameters and space group compatible with the experimental X-ray diffraction pattern were initially determined using a Pawley profile-fitting procedure. ${ }^{54}$ The Pawley refinement, which minimizes the weighted $R$-factor, $R_{\mathrm{wp}}$, describing the agreement between the experimental pattern and the simulated one, helps to confirm the indexing result and to analyze the systematic absences, and thus to determine the possible space groups. Two space groups were found to be compatible with the Pawley refinement, Pmmn

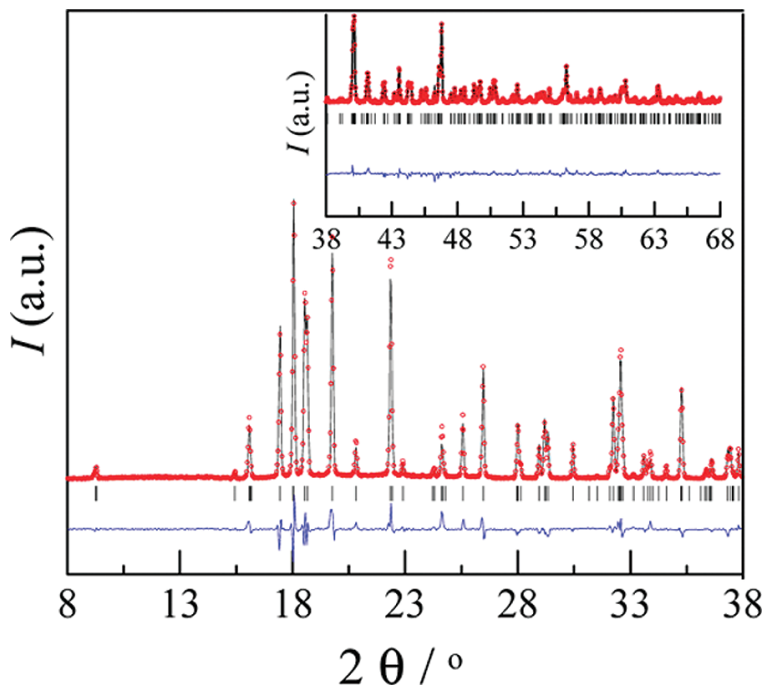

Figure 1. Experimental (red circles) and calculated (black line) diffraction patterns along with the difference profile (blue line) of orthorhombic phase III of $\left(\mathrm{CH}_{3}\right)_{3} \mathrm{CBr}$ (at $180 \mathrm{~K}$ ). Inset corresponds to the scale for the data with $2 \theta>38^{\circ}$.

and $P m 2_{1} n$, both involving $Z=8$ molecules per unit cell and the same systematic absences. Nevertheless, the former one implies one independent molecule and the latter two independent molecules in general positions for reaching $Z=8$ by density requirements. In both cases, a Powder Solve run did not succeed. Another attempt was performed in space group $P 1$ by placing eight independent molecules in the lattice and applying $90^{\circ}$ constraints on the lattice angle values. By this procedure, two clear elements of symmetry emerged: on one side a clear binary axis $\left(2_{1}\right)$ and, on the other hand, the noncentrosymmetric character of the unit cell discarding the Pmmn space group. A new attempt in $P 2_{1}$ space group revealed the solution. Finally in $P m n 2_{1}$ ( $b$ and $c$ axes being permuted), the independent molecules, one in the general position and the two other ones on the mirror $(Z=4+2+$ $2=8$ ) were fully positioned and the structure was coherently solved by combining Rietveld refinement and energy lattice minimization (using Forcite with refinement of the molecular geometry). Preferred-orientation corrections of the powder sample were initially searched within the Powder Solve module by means of the March-Dollase function ${ }^{55}$ and by the Rietveld-Toraya function ${ }^{56,57}$ for the final Rietveld refinement.

The experimental collected and the final calculated profiles are shown in Figure 1 together with the difference plot between them. The parameters refined in the procedure are collected in Table 2 and the coordinates of the atoms of the asymmetric unit are given in Table 3 .

3.2. Lattice Parameter As a Function of Temperature. X-ray powder diffraction experiments were performed on heating from $90 \mathrm{~K}$ up to the melting temperature, thus covering all the solid phases in order to determine the volume changes at the phase transitions and the thermal expansion tensor. The lattice parameters were refined at each temperature (Figure 2) as previously described for phase III and using a Pawley profile-fitting procedure.

Then refined lattice parameters and unit cell volume were fitted as a function of temperature by means of a standard least-squares method. The equations for these variations are gathered in Table 4. The calculated molar volume for the whole temperature range of the solid phases as well as for 
Table 2. Results from the Rietveld Refinement of Phase III of $\left(\mathrm{CH}_{3}\right)_{3} \mathrm{CBr}$ at $180 \mathrm{~K}$

$$
\begin{gathered}
R_{\mathrm{wp}} \quad\left[\left[\sum_{i} w_{i}\left|c Y^{\operatorname{sim}}\left(2 \theta_{i}\right)-I^{\exp }\left(2 \theta_{i}\right)+Y^{\mathrm{back}}\left(2 \theta_{i}\right)\right|^{2}\right] / \sum_{i} w_{i}\left|I^{\exp }\left(2 \theta_{i}\right)\right|^{2}\right]^{1 / 2} \\
R_{\mathrm{p}} \quad\left[\sum_{i}\left|c Y^{\operatorname{sim}}\left(2 \theta_{i}\right)-I^{\exp }\left(2 \theta_{i}\right)+Y^{\text {back }}\left(2 \theta_{i}\right)\right|\right] / \sum_{i}\left|I^{\exp }\left(2 \theta_{i}\right)\right|
\end{gathered}
$$

\begin{tabular}{ll}
\hline \multicolumn{1}{c}{ parameter } & \multicolumn{1}{c}{ value } \\
\hline $2 \theta$ angular range & $8-90$ \\
$2 \theta$ shift (zero correction) & $0.0097 \pm 0.0005$ \\
profile parameters & \\
$\mathrm{Na}$ & $0.220 \pm 0.021$ \\
$\mathrm{Nb}$ & $0.0029 \pm 0.0008$ \\
lattice parameters & \\
$a / \AA$ & $19.1350 \pm 0.000$ \\
$b / \AA$ & $5.7378 \pm 0.0001$ \\
$c / \AA$ & $10.9626 \pm 0.0002$ \\
reliability parameters & \\
$R_{\mathrm{wp}}$ & $7.73 \%$ \\
$R_{\mathrm{p}}$ & $5.56 \%$ \\
peak width parameters & \\
$u$ & $0.0492 \pm 0.0052$ \\
$v$ & $-0.0294 \pm 0.0033$ \\
$w$ & $0.0135 \pm 0.0005$ \\
overall isotropic temperature factor, $U / \AA^{2}$ & $0.0446 \pm 0.0006$ \\
preferred orientation (Rietveld-Toraya function) & \\
$a^{*}$ & 0.000 \\
$b^{*}$ & $0.902 \pm 0.006$ \\
$c^{*}$ & $0.430 \pm 0.013$ \\
$\mathrm{G} 2$ & -0.882 \\
$\mathrm{G} 1$ & 0.328
\end{tabular}

the liquid phase (obtained from Density Measurements) is shown in Figure 3.

3.3. Thermodynamic Results. Temperature and enthalpy changes at the solid solid and melting transitions determined by means of DSC (see Figure 4) at normal pressure are summarized in Table 1. It can be seen that results match up with those previously reported, within the experimental error.

High-pressure DTA experiments were conducted to determine the solid solid and melting temperature transitions as a function of pressure. Figure 4 displays an example at $50 \mathrm{MPa}$ and Figure $5 \mathrm{a}$ displays the pressure temperature ( $p \quad T)$ phase diagram. It is worth noticing that, within the pressure range studied, there is not an appearance of a new phase (unlike the behavior of $\mathrm{tBCl},{ }^{58}{ }^{60}$ see Figure $5 \mathrm{~b}$ ) and, in addition, the two-phase equilibrium lines diverge with pressure.

High-pressure density measurements were undertaken up to $300 \mathrm{MPa}$ for several representative isotherms. The results of the pressure transition at each measured temperature were used to complete the $p \quad T$ phase diagram (Figure 5a) as well as to determine the volume changes as a function of pressure for the phase transitions. Such volume changes are shown in Figure 6. It is worth noticing that values obtained at normal pressure from X-ray diffraction (solid phases) and density (liquid phase) measurements agree coherently with those obtained as a function of pressure.

\section{Discussion}

The most striking features of the structure of phase III of $\mathrm{tBBr}$ are the number of molecules forming the asymmetric unit $Z^{\prime}=(1+1 / 2+1 / 2)$ and the absence of a center of symmetry which gives rise to noticeable differences in the
Table 3. Fractional Atomic Coordinates for Phase III of $\left(\mathrm{CH}_{3}\right)_{3} \mathrm{CBr}$ at $180 \mathrm{~K}$

\begin{tabular}{lllr}
\hline atom & \multicolumn{1}{c}{$X$} & \multicolumn{1}{c}{$Y$} & $\mathrm{Z}$ \\
\hline Br35 & $0.28933(15)$ & $0.7666(7)$ & $0.5449(11)$ \\
C31 & $0.2603(4)$ & $0.6181(10)$ & $0.3933(11)$ \\
C32 & $0.2366(4)$ & $0.8096(15)$ & $0.3052(12)$ \\
H321 & $0.2791(3)$ & $0.9335(13)$ & $0.2853(11)$ \\
H322 & $0.2193(6)$ & $0.7346(20)$ & $0.2177(12)$ \\
H323 & $0.1924(2)$ & $0.9097(17)$ & $0.3428(11)$ \\
C33 & $0.1999(4)$ & $0.4515(13)$ & $0.4217(11)$ \\
H331 & $0.1813(6)$ & $0.3645(18)$ & $0.3382(11)$ \\
H332 & $0.2157(4)$ & $0.3145(10)$ & $0.4864(11)$ \\
H333 & $0.1551(3)$ & $0.5449(15)$ & $0.4617(12)$ \\
C34 & $0.3230(5)$ & $0.4843(8)$ & $0.3413(12)$ \\
H341 & $0.3091(8)$ & $0.3980(12)$ & $0.2548(12)$ \\
H342 & $0.3674(5)$ & $0.6012(7)$ & $0.3228(13)$ \\
H343 & $0.3411(5)$ & $0.3481(6)$ & $0.4048(13)$ \\
& & & \\
Br5 & 0.00000 & $1.0650(10)$ & $0.7869(7)$ \\
C1 & 0.00000 & $0.9562(10)$ & $0.6187(7)$ \\
C2 & $-0.0659(4)$ & $1.0488(10)$ & $0.5558(7)$ \\
H21 & $-0.0681(5)$ & $0.9910(10)$ & $0.4600(7)$ \\
H22 & $-0.0674(4)$ & $1.2407(10)$ & $0.5558(7)$ \\
H23 & $-0.1136(5)$ & $0.9860(10)$ & $0.6013(7)$ \\
C3 & 0.00000 & $0.6893(10)$ & $0.6209(7)$ \\
H32 & 0.00000 & $0.6176(10)$ & $0.5277(7)$ \\
H33 & $-0.0465(3)$ & $0.6206(10)$ & $0.6681(7)$ \\
Br15 & & & \\
C11 & 0.00000 & $0.4661(10)$ & $0.2886(7)$ \\
C12 & 0.00000 & $0.6516(10)$ & $0.1400(7)$ \\
H121 & $-0.0660(6)$ & $0.8029(10)$ & $0.1392(7)$ \\
H122 & $-0.0680(5)$ & $0.9202(10)$ & $0.2187(7)$ \\
H123 & $-0.0681(4)$ & $0.9123(10)$ & $0.0566(7)$ \\
C13 & $0.1138(5)$ & $0.6954(10)$ & $0.1406(7)$ \\
H132 & 0.00000 & $0.4840(10)$ & $0.0312(7)$ \\
H133 & $-0.0465(5)$ & $0.5808(10)$ & $-0.0554(7)$ \\
& & $0.3708(10)$ & $0.0316(7)$
\end{tabular}
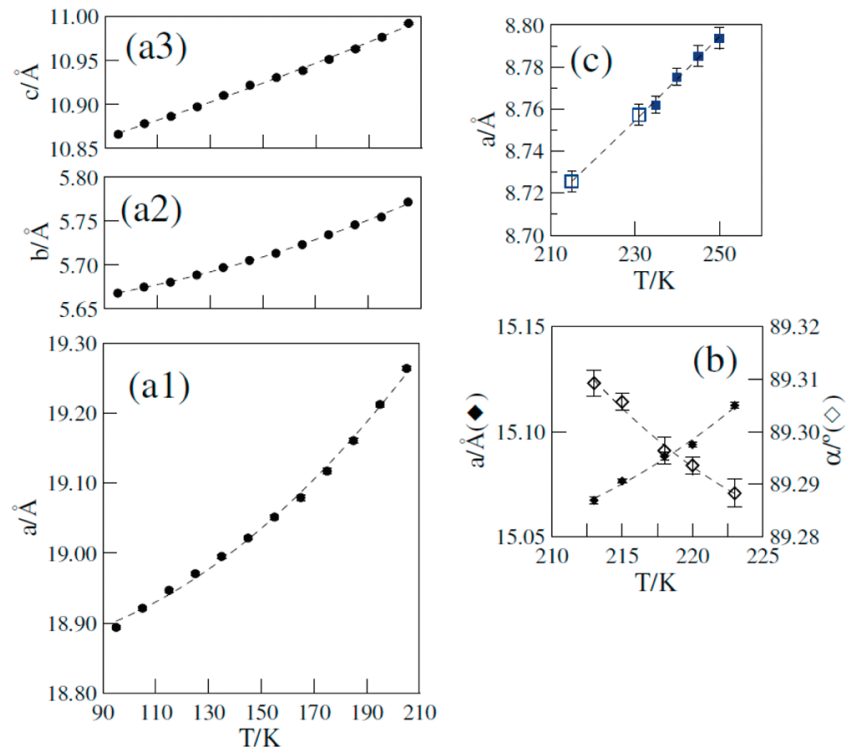

Figure 2. Lattice parameters at normal pressure as a function of temperature for the (a) orthorhombic $\left(P m n 2_{1}\right)$, (b) rhombohedral, and (c) face centered cubic phases of $\left(\mathrm{CH}_{3}\right)_{3} \mathrm{CBr}$. Empty symbols in panel (c) correspond to the supercooled phase I.

molecular arrangement of the motifs in the lattice structure compared to those of $\mathrm{tBCl}$ and $\mathrm{tBCN}$ (Figure 7).

For the low-temperature phases of $\mathrm{tBCl}$ and $\mathrm{tBCN}$, with space groups $P 2_{1} / m$, the mirror plane of the molecule has to be coincident with the mirror plane of the space group, and thus the molecule can only rotate around $b$ and the $Y_{\mathrm{o}}$ coordinate of the center of the asymmetric unit (formed by one molecule) 
Table 4. Polynomial Equations $p=p_{0}+p_{1} T+p_{2} T^{2}$ ( $T$ in $\mathrm{K}$ and $p$ in $\AA$ or deg for $\alpha$ ) to Which the Lattice Parameters Were Fitted As a Function of Temperature $^{a}$

\begin{tabular}{cccccc}
\hline phase & temperature range $/ \mathrm{K}$ & parameter & $p_{0}$ & \multicolumn{1}{c}{$p_{1} \cdot 10^{3}$} & $p_{2} \cdot 10^{5}$ \\
\hline III & $95-205$ & $a / \AA$ & $18.885(39)$ & $-1.210(54)$ & $1.475(18)$ \\
& & $b / \AA$ & $5.644(7)$ & $-0.058(10)$ & $0.337(34)$ \\
II & & $c / \AA$ & $10.789(12)$ & $0.698(17)$ & $0.138(58)$ \\
& $213-223$ & $a / \AA$ & $14.146(66)$ & $4.320(30)$ & 1.2 \\
I & $210^{b} 250$ & $a / \AA$ & $89.770(36)$ & $-2.160(16)$ & 0.7 \\
& & $a / \AA$ & $8.303(13)$ & $1.960(5)$ & 0.2 \\
\end{tabular}

${ }^{a} R$ is the reliability factor $\left(R^{2} \quad \sum\left[y_{\mathrm{o}}-y_{\mathrm{c}}\right]^{2} / y_{\mathrm{c}}{ }^{2}\right) \cdot{ }^{b}$ For phase I the supercooled temperature domain is enclosed.

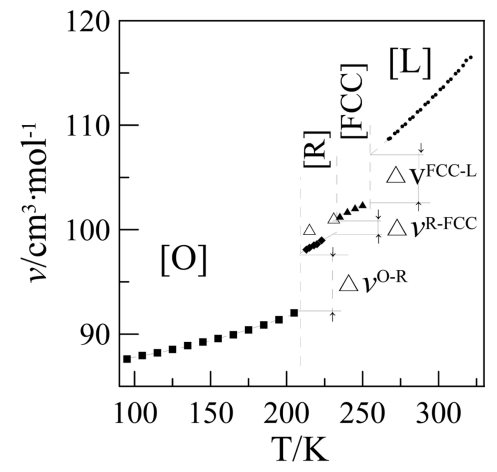

Figure 3. Molar volume at normal pressure for the orthorhombic $(\mathrm{O})$, rhombohedral (R), face centered cubic (FCC), and liquid (L) phases of $\left(\mathrm{CH}_{3}\right)_{3} \mathrm{CBr}$ as a function of temperature. Empty triangles correspond to the supercooled FCC phase.

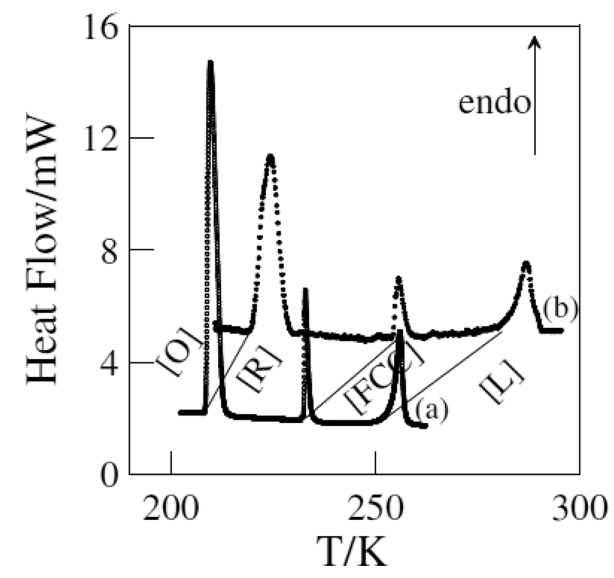

Figure 4. DSC curve at normal pressure (a) and high pressure DTA curve at $50 \mathrm{MPa}(\mathrm{b})$ for $\left(\mathrm{CH}_{3}\right)_{3} \mathrm{CBr}$.

is set as $1 / 4$. Consequently, the molecules are arranged in a head-to-tail configuration with the 3 -fold $C_{3}^{\prime}$-axis (dipole axis of the molecule) almost parallel to the $c$ direction in the $a c$ plane (tilts are about $2.2^{\circ}$ and $4^{\circ}$ for $\mathrm{tBCl}^{8,23}$ and $\mathrm{tBCN},{ }^{20}$ respectively) (see Figure $7 \mathrm{~b}, \mathrm{c}$ ). In this way, the adjacent rows of molecules along the $c$ direction (with parallel $C_{3}^{\prime}$-axis) are inverted with respect to each other, and in spite of the rotation about the 3-fold molecular axis, the inverted molecules get closer with a high packing coefficient.

As far as the structure of phase III of $\mathrm{tBBr}$ is concerned, a noticeable difference is inferred. Because of the noncentrosymmetric structure ( $P m n 2_{1}$ space group), all the molecules of the unit lattice point out closely in the same direction (Figure 7a). The four molecules corresponding to the symmetry operations of the molecule in a general position of the asymmetric unit stack with the $C_{3}^{\prime}$-axis tilted around $31.46^{\circ}$
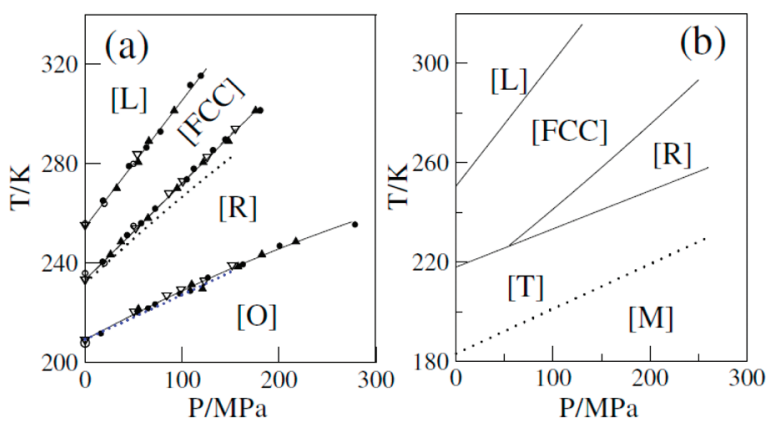

Figure 5. (a) Pressure temperature phase diagram of $\left(\mathrm{CH}_{3}\right)_{3} \mathrm{CBr}$ from high pressure DTA (filled circles, ${ }^{44}$ dotted lines; ${ }^{43}$ empty triangles, this work), dielectric measurements (empty circles ${ }^{44}$ ), high pressure density measurements (filled triangles, this work), and (b) pressure temperature phase diagram of $\left(\mathrm{CH}_{3}\right)_{3} \mathrm{CCl}^{58} \quad 60$

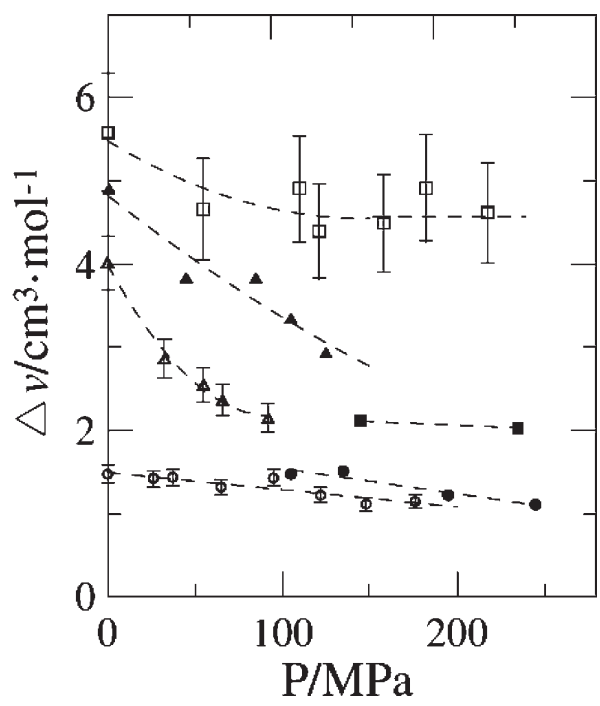

Figure 6. Volume changes as a function of pressure for the phase transitions of $\left(\mathrm{CH}_{3}\right)_{3} \mathrm{CBr}$ (empty symbols) and $\mathrm{tBCl}$ (filled symbols) from the literature. ${ }^{60} \mathrm{O}$ R (T R for $\mathrm{tBCl}$ ), squares; R FCC (circles), and FCC L (triangles).

with respect to the $c$ axis of the lattice (see Figure 7a). For the two molecules of the asymmetric unit in a special position, the angles of their $C_{3}^{\prime}$-axis with respect to the $c$-axis are $18.80^{\circ}$ and $32.75^{\circ}$.

Such a packing arrangement gives rise to rows of molecules along the crystallographic $c$-axis forming a zigzag and without inversion of molecules and thus, to some extent, to a less effective packing than that of the $\mathrm{tBCl}$ within their lowtemperature structure $\left(P 2_{1} / m\right)$. As far as the packing of tBCN is concerned, the elongated $\mathrm{CN}$ group gives rise to a noticeably increased distance between the molecules along the $c$-axis (around $6.0 \AA$ for $\mathrm{tBCl}$ and $6.7 \AA$ for $\mathrm{tBCN}$, see Figures $7 \mathrm{~b}, \mathrm{c}$ ). 
(A)

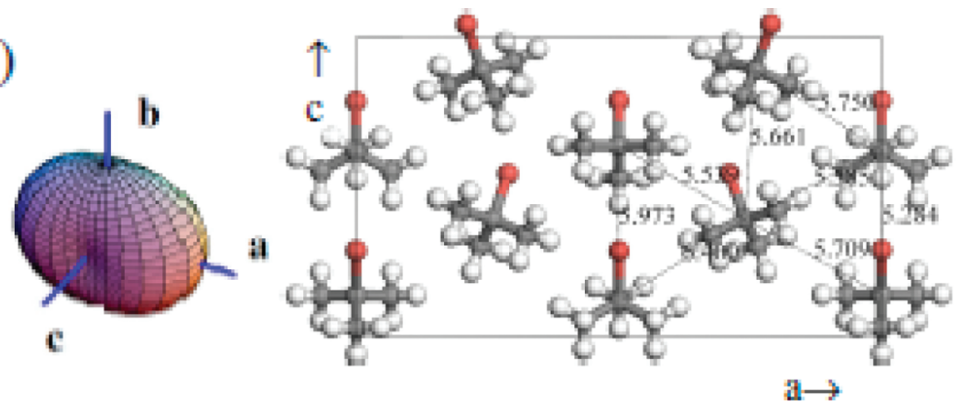

(B)
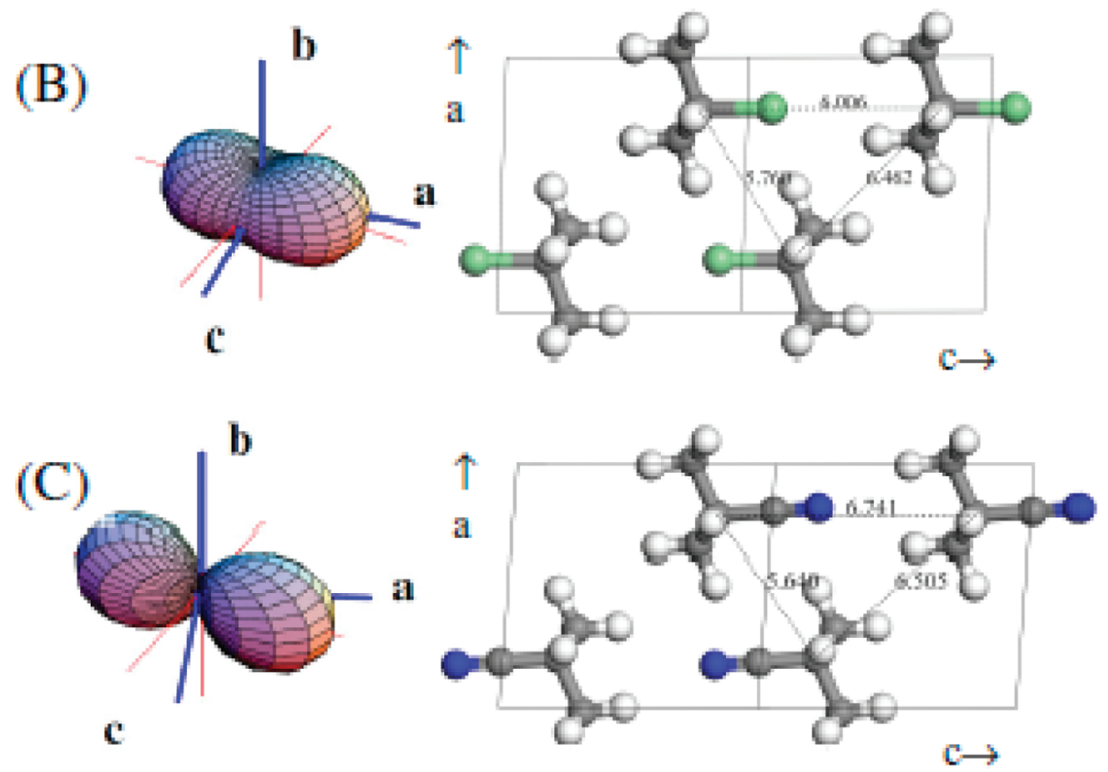

Figure 7. $(0 \mathrm{k} 0)$ crystallographic planes (right panels) of the orthorhombic phase III of $\left(\mathrm{CH}_{3}\right)_{3} \mathrm{CBr}$ at $185 \mathrm{~K}(\mathrm{~A})$ and monoclinic $\left(P 2_{1} / \mathrm{m}\right)$ phases of $\left(\mathrm{CH}_{3}\right)_{3} \mathrm{CCl}$ at $123 \mathrm{~K}^{8}(\mathrm{~B})$ and $\left(\mathrm{CH}_{3}\right)_{3} \mathrm{CCN}$ at $147 \mathrm{~K}^{20}(\mathrm{C})$ together with the thermal expansion tensors (left panels, blue: crystallographic axes; red: principal axes).
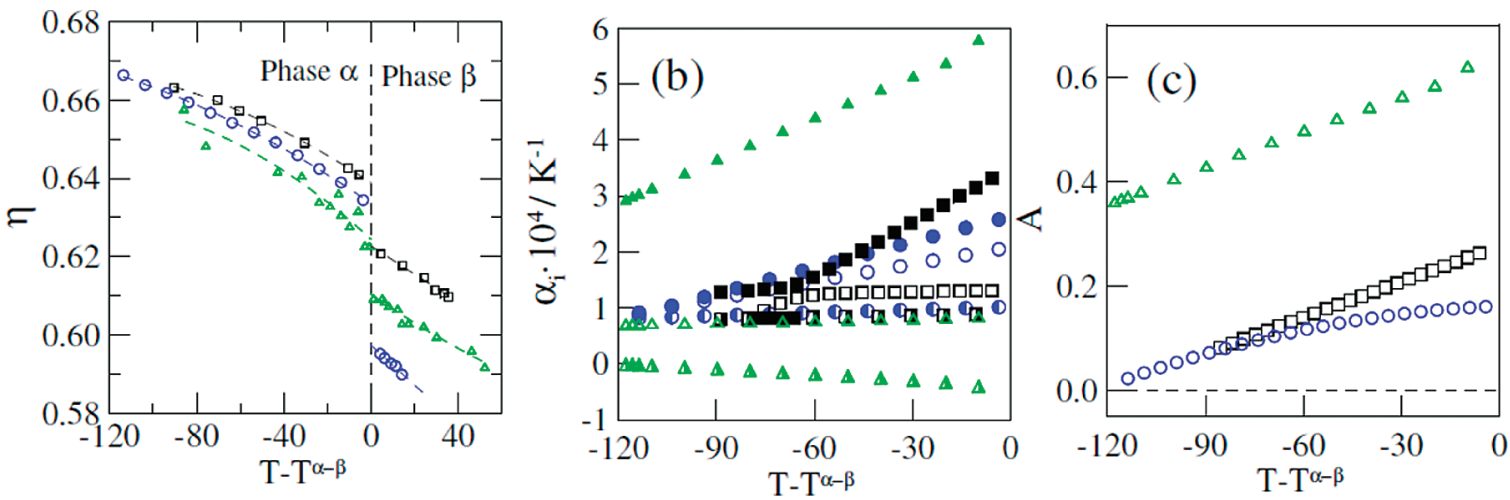

Figure 8. (a) Packing coefficient, (b) principal coefficients of the thermal expansion tensor $\left(\alpha_{1}\right.$, filled symbols; $\alpha_{2}$, half filled symbols; $\alpha_{3}$, empty symbols), and (c) aspherism index as a function of the scaled transition temperature from the low temperature phase $\left(\left(\mathrm{CH}_{3}\right)_{3} \mathrm{CBr}_{3}\right.$, blue circles; $\left(\mathrm{CH}_{3}\right)_{3} \mathrm{CCl}$, black squares; $\left(\mathrm{CH}_{3}\right)_{3} \mathrm{CCN}$, green triangles).

Such a difference is strictly coming from the higher van der Waals volume of the $\mathrm{CN}$ group in comparison with that of the $\mathrm{Cl}$ atom as can be seen by comparing the similar distance between the $\mathrm{N}$ or $\mathrm{Cl}$ atoms to the central carbon of the closest molecule (4.1 and $4.2 \AA$, respectively). This fact induces then a considerable reduction of the packing coefficient of $\mathrm{tBCN}$ with respect to $\mathrm{tBCl}$.

Figure 8 a shows the variation of the packing coefficient $\eta=$ $V_{\mathrm{m}} /(V / Z)$, in which $V_{\mathrm{m}}$ is the van der Waals volume of the molecule $\left(\mathrm{tBCl}=93.05 \AA^{3} ; \mathrm{tBBr}=96.97 \AA^{3} ; \mathrm{tBCN}=95.80 \AA^{3}\right)$ and $V / Z$ is the volume occupied by a molecule in the lattice) for the different phases as a function of the scaled temperature with respect to the III to II phase transition (II I for $\mathrm{tBCN}$ compound). The molecular van der Waals volumes were computed according to the Kitaigorodsky's method ${ }^{61}$ with interatomic chemical bonds from the reported structures and atomic van der Waals radii obtained from Material Studio database (C: $1.70 \AA$; $\mathrm{H}: 1.20 \AA$; $\mathrm{Cl}: 1.75 \AA$; $\mathrm{Br}: 1.85 \AA$; N: $1.54 \AA$ ).

As can be seen, the packing coefficients of the lowtemperature phases, where the highest intermolecular interactions 
are known to be present, are higher than those of the tetragonal (for $\mathrm{tBCl}$ and $\mathrm{tBCN}$ ) and rhombohedral (tBBr) phases, for which interactions have been "softened" due to the appearance of some kind of disorder. This fact is especially noticeable for $\mathrm{tBBr}$, for which the packing variation at the III II transition is the highest, a consequence of the OD character of phase II as clearly indicated by the entropy change at the III to II transition (the highest for $\mathrm{tBBr}$ compound, see Table 1) as well as by the large fluctuations of the dipole axis reported from NMR measurements. ${ }^{5,11} 13,17$ It should be borne in mind that for phase II of $\mathrm{tBCl}$ and phase I of tBCN (both of tetragonal symmetry) the disorder of the molecules consists only of small fluctuations (librational motions) of the dipole axes. ${ }^{16}$

It is worth noting that the packing values of OD fcc phases for $\mathrm{tBBr}$ and $\mathrm{tBCl}$ (not reported in Figure $8 \mathrm{a}$ ) are relatively low (ca. 0.57) when compared to other plastic phases for which the existence of dynamical hydrogen bonds has been clearly demonstrated. ${ }^{62,63}$

As for the low-temperature phase for all these compounds, the $a$ lattice parameter changes faster than $b$ and $c$ with temperature (Figure 2) because the nearest neighbors molecules in this direction have a close packing of the tertiary butyl groups. Nevertheless, this packing should be compatible with the increasing of the reorientational frequency of the fluctuations of the dipole axis, around which ( $C_{3}^{\prime}$-axis) uniaxial molecular reorientations between the three equivalent positions, and thus large thermal expansion occurs in such a direction. This behavior can be straightforwardly seen by analyzing the thermal expansion tensor. The thermal expansion tensor expresses the cell deformation $\mathrm{d} U$ due to a temperature change $\mathrm{d} T$ by means of a second-rank tensor at a given temperature, $\mathrm{d} U=\alpha_{i j} \mathrm{~d} T, \alpha_{i j}$ being the principal coefficients (eigenvalues) of the thermal-expansion tensor. The principal axes (eigenvectors) of the tensor describe the highest and the weakest deformations related to the directions of the soft and hard directions, respectively, of the intermolecular interactions. ${ }^{64,65}$ Details of the procedure and method for the calculations of the tensor have been published elsewhere. $^{65}$

For a monoclinic lattice, the tensor is defined by three principal coefficients and an angle between the direction of one of the principal directions $\left(\alpha_{i}\right)$ and one lattice axis, $\alpha_{3}$ being coincident with the 2-fold axis $b$ of the lattice. For an orthorhombic lattice, the principal directions should be coincident with the lattice axes of the crystal according to the Newmann's principle (for which the thermal-expansion tensor has to display the point group symmetries of the crystal).

Left panels of Figure 7 display the tridimensional thermalexpansion tensor for the low-temperature phases of $\mathrm{tBBr}$, $\mathrm{tBCl}$, and $\mathrm{tBCN}$. As can be inferred from that figure, the highest deformation ("soft" direction) corresponds closely to the [100] crystallographic direction in low-temperature phases of $\mathrm{tBCl}$ and $\mathrm{tBCN}$, and exactly to such a direction for $\mathrm{tBBr}$. On the contrary, the lowest deformation corresponds to the (100) plane ("hard" plane) for all the compounds. In the case of tBCN, the $\alpha_{2}$ direction (close to [001] crystallographic direction) is even negative (contraction) in the displayed temperature range of the monoclinic phase. For $\mathrm{tBCl}$ and especially for $\mathrm{tBCN}$ the large thermal expansion along the [100] direction is coupled with the strong interaction along the $c$ axis (parallel to the molecular dipoles) in such a way that the $C_{3}^{\prime}$-rotation of the tert-butyl group is less impeded with increasing temperature as indicated by the increase of the frequency of reorientations around that axis which cause the molecules to move further apart in the $a$ crystallographic direction as the temperature increases. This is not the case for $\mathrm{tBBr}$, for which the anisotropy of the thermal expansion tensor is lower as can be inferred from the relatively close values of the principal coefficients of the tensor (Figure 8b).

The anisotropy of the intermolecular interactions can be accounted for by means of the aspherism index, defined as

$$
A=\left(\frac{2}{3}\right)\left[1 \quad\left(3 \beta / \alpha_{v}^{2}\right)\right]^{1 / 2}
$$

where $\beta=\alpha_{1} \alpha_{2}+\alpha_{2} \alpha_{3}+\alpha_{1} \alpha_{3}{ }^{66}$ This coefficient reaches the zero value when the thermal expansion tensor is isotropic. For the low-temperature phase of the compounds reported in Figure 8c, the aspherism index increases with temperature as a consequence of the increase in the anisotropy of the intermolecular interactions. The highest values are those corresponding to $\mathrm{tBCN}$ thus evidencing the strong dipole dipole interaction within the head-to-tail arrangement of the molecules.

The ordered or partially disordered character of the involved phases has consequences in the entropy as well as in the volume changes at the phase transitions. When comparing such volume changes (Figure 6), it comes clear the similarity between the R to FCC transitions for both compounds (even though phase $\mathrm{R}$ only exists at high-pressure for $\mathrm{tBCl}$ ) and the strong difference between $\mathrm{T}$ to $\mathrm{R}(\mathrm{tBCl})$ and $\mathrm{O}$ to $\mathrm{R}(\mathrm{tBBr})$, which show that the $\mathrm{T}$ phase of $\mathrm{tBCl}$ has a partial disorder (librations around the dipole molecular axes) while $\mathrm{O}$ phase of tBBr is fully ordered, as the $P 2_{1} / m$ low-temperature phase of $\mathrm{tBCl}$. In this context, tetragonal phase I of $\mathrm{tBCN}$ should not be considered as an orientationally disordered phase but a partially ordered phase similar to the tetragonal phase of $\mathrm{tBCl}$.

\section{Conclusions}

The polymorphism of $\left(\mathrm{CH}_{3}\right)_{3} \mathrm{CBr}$ has been studied from $90 \mathrm{~K}$ to the liquid state as well as a function of pressure (until $300 \mathrm{MPa})$.

The long time unknown structure of the low-temperature phase of $\left(\mathrm{CH}_{3}\right)_{3} \mathrm{CBr}$ has been determined to be orthorhombic with space group $P m n 2_{1}$. It involves eight molecules per unit cell $(Z=8)$ with an asymmetric unit $\left(Z^{\prime}\right)$ formed by one molecule in a general position and two additional molecules placed in a mirror (then contributing as one-half each one), that is, $Z^{\prime}=1+1 / 2+1 / 2$. The similarities and differences with related tert-butyl compounds as $\left(\mathrm{CH}_{3}\right)_{3} \mathrm{CCl}$ and $\left(\mathrm{CH}_{3}\right)_{3} \mathrm{CCN}$ for which the structures of the low-temperatures phases have been previously reported have been highlighted. In particular, through the thermal-expansion tensor, the differences in the role played by the dipole dipole interactions seem to be the main cause of the structural differences.

The pressure temperature phase diagram has been determined within the range of $0.1300 \mathrm{MPa}$. The polymorphism sequence at normal pressure is kept whatever the pressure within the studied range. From density measurements as a function of pressure, volume changes have been determined giving a coherent physical image of the determined structure of the orthorhombic phase as well as for the previous lattice determinations of the orientationally disordered phases II (rhombohedral) and I (FCC). 
Acknowledgment. This work was supported by the Spanish Ministry of Science and Innovation (Grant FIS2008-00837) and the Catalan Government (Grant 2009SGR-1251).

\section{References}

(1) Guillon, D. Phase Transitions in Rod Like Liquid Crystals; Demus, D., Goodby, J., Gray, G. W., Spiess, H.-W, Will, V., Eds.; Wiley-VCH: Weinheim, Germany, 1998; Vol. 2A, Chapter II, pp 23-46.

(2) Parsonage, N. G.; Staveley, L. A. K. Disorder in Crystals; Clarendon: Oxford, 1978.

(3) Rudman, R. J. Mol. Struct. 2001, 569, 157.

(4) Reuter, J.; Busing, D.; Tamarit, J. Ll.; Wurflinger, A. J. Mater. Chem. 1997, 7, 41.

(5) Hasebe, T. Bull. Chem. Soc. Jpn. 1990, 63, 2877.

(6) Urban, S. Adv. Mol. Relax. Interact. Processes 1981, 21, 221.

(7) Chen, J.; Bartell, L. S. J. Phys. Chem. 1993, 97, 10645.

(8) Tamarit, J. Ll.; López, D. O.; Alcobé, X.; Barrio, M.; Salud, J.; Pardo, L. C. Chem. Mater. 2000, 12, 555.

(9) Jenau, M.; Reuter, J.; Tamarit, J. Ll.; Wurflinger, A. J. Chem. Soc. Faraday Trans. 1996, 92, 1899.

(10) Rey, R.; Pardo, L. C.; Llanta, E.; Ando, K.; López, D. O.; Tamarit, J. Ll.; Barrio, M. J. Chem. Phys. 2000, 112, 7505.

(11) Aksnes, D. W.; Ramstad, K.; Bjorlykke, O. P. Magn. Reson. Chem. 1987, 25, 1063 .

(12) Hasebe, T.; Strange, J. H.; Nakamura, N.; Chihara, H. J. Chem. Soc. Faraday Trans. 2 1985, 81, 749.

(13) Pettitt, B. A.; Lewis, J. S.; Wasylishen, E.; Danchura, W.; Tomchuk, E.; Bock, E. J. Magn. Reson. 1981, 44, 508.

(14) Richardson, R. M.; Taylor, P. Mol. Phys. 1984, 52, 525.

(15) Schwartz, R. S.; Post, B.; Fankuchen, I. J. Am. Chem. Soc. 1951, 73, 4490.

(16) Frost, J. C.; Leadbetter, A. J.; Ward, R. C. J. Chem. Soc. Faraday Trans. 2 1982, 78, 1009.

(17) Leadbetter, A. J.; Ward, R. C.; Richardson, R. M. J. Chem. Soc. Faraday Trans. 2 1985, 81, 1067.

(18) Bertie, J. E.; Sunder, S. Spectrochim. Acta 1974, 1373.

(19) Bertie, J. E.; Sunder, S. J. Chem. Phys. 1973, 59, 498.

(20) Frost, J. C.; Leadbetter, A. J.; Richardson, R. M.; Ward, R. C.; Goodby, J. W.; Gray, G. W.; Pawley, G. S. J. Chem. Soc. Faraday Trans.2 1982, 78, 179.

(21) Pardo, L. C.; Barrio, M.; Tamarit, J. Ll.; López, D. O.; Salud, J.; Negrier, P.; Mondieig, D. Phys. Chem. Chem. Phys. 2001, 3, 2644.

(22) Urban, S.; Domoslawski, J.; Tomkowicz, Z. Mater. Sci. 1978, IV/3, 91.

(23) Rudman, R. J. Mol. Struct. 1999, 485, 281.

(24) Rogers, R. D. Cryst. Growth Des. 2004, 4, 1085 and references within this special issue "Polymorphism in Crystals".

(25) Maddox, J. Nature 1988, 335, 201.

(26) Gavezzotti, A. Acc. Chem. Res. 1994, 27, 309.

(27) Dunitz, J. D. Chem. Commun. 2003, 545.

(28) Barrio, M.; Pardo, L. C.; Tamarit, J. Ll.; Negrier, P.; Salud, J.; López, D. O.; Mondieig, D. J. Phys. Chem. B 2006, 110, 12096.

(29) Hasebe, T.; Ohtani, S. J. Chem. Soc. Faraday Trans. 1 1988, 84, 187.

(30) Tamarit, J. Ll.; Barrio, M.; Pardo, L. C.; Negrier, P.; Mondieig, D. J. Phys.: Condens. Matter 2008, 20, 244110.

(31) Negrier, P.; Pardo, L. C.; Salud, J.; Tamarit, J. Ll.; Barrio, M.; Lopez, D. O.; Wurflinger, A.; Mondieig, D. Chem. Mater. 2002, 14, 1921.
(32) Pardo, L. C.; Barrio, M.; Tamarit, J. Ll.; Negrier, P.; Lopez, D. O.; Salud, J.; Mondieig, D. J. Phys. Chem. B 2001, 105, 10326.

(33) Barrio, M.; Tamarit, J. Ll.; Céolin, R.; Pardo, L. C.; Negrier, P.; Mondieig, D. Chem. Phys. 2009, 358, 156.

(34) McMillan, P. F. Nat. Mater. 2007, 6, 7.

(35) McMillan, P. F. Chem. Soc. Rev. 2006, 35, 855.

(36) Boldyreva, E. Cryst. Growth Des. 2007, 7, 1662.

(37) Steed, J. W. CrystEngComm 2003, 5, 169.

(38) Nicho, G. S.; Clegg, W. CrystEngComm 2007, 9, 959.

(39) Babu, N. J.; Nangia, A. CrystEngComm 2007, 9, 980.

(40) Anderson, K. M.; Steed, J. W. CrystEngComm 2007, 9, 328.

(41) Desiraju, G. R. CrystEngComm 2007, 9, 91.

(42) Wilson, A. J. C. Acta Cryst. A 1993, 49, 795.

(43) Wenzel, U.; Schneider, G. M. Thermochim. Acta 1986, 109, 111.

(44) Kreul, H. G.; Hartmann, M.; Edelmann, R.; Wurflinger, A. Ber. Bunsenges. Phys. Chem. 1989, 93, 612.

(45) Ballon, J.; Comparat, V.; Pouxe, J. Nucl. Instrum. Methods 1983, 217, 213.

(46) Evain, M.; Deniard, P.; Jouanneaux, A.; Brec, R. J. Appl. Crystal $\log r .1993,26,563$.

(47) Engel, G. E.; Wilke, S.; Konig, O.; Harris, K. D. M.; Leusen, F. J. J. J. Appl. Crystallogr. 1999, 32, 1169.

(48) MS Modeling (Material Studio) version 4.1: http://www.accelrys. com $/$ mstudio $/ \mathrm{ms}$ modeling.

(49) Wurflinger, A. Ber. Bunsen Gesell. Phys. Chem. Chem. Phys. 1975, $79,1195$.

(50) Randzio, S. L.; Grolier, J. P. E.; Quint, J. R.; Eatough, D. J.; Lewis, E. A.; Hansen, L. D. Int. J. Thermophys. 1994, 15, 415.

(51) Mopsik, F. I. J. Res. Nat. Bur. Stand. Sec. A 1967, 71, 287.

(52) Wurflinger, A.; Sandmann, M.; Weissflog, W. Z. Naturforsch. Teil $A$ 2000, 55, 823 .

(53) Neumann, M. A. J. Appl. Crystallogr. 2003, 36, 356.

(54) Pawley, G. S. J. Appl. Crystallogr. 1981, 14, 357.

(55) Dollase, W. A. J. Appl. Crystallogr. 1986, 19, 267.

(56) Toraya, H.; Marumo, F. Mineral. J. 1981, 10, 211.

(57) Rietveld, H. M. J. Appl. Crystallogr. 1969, 2, 6571.

(58) Wenzel, U.; Schneider, G. M. Mol. Cryst. Liq. Cryst. Lett. Sect. 1982, 72, 255.

(59) Barrio, M.; de Oliveira, P.; Céolin, R.; López, D. O.; Tamarit, J. Ll. Chem. Mater. 2002, 14, 851

(60) Wilmers, J.; Briese, M.; Wurflinger, A. Mol. Cryst. Liq. Cryst. 1984, 107, 293.

(61) Kitaigorodsky, A. I. Mixed Crystals; Berlin: Springer-Verlag, 1984.

(62) Barrio, M.; López, D. O.; Tamarit, J. Ll.; Negrier, P.; Haget, Y. J. Solid State Chem. 1996, 124, 29.

(63) Tamarit, J. Ll.; Barrio, M.; López, D. O.; Haget, Y. J. Appl. Crystallogr. 1997, 30, 118.

(64) Garnier, P.; Calvarin, G.; Weigel, D. J. Chim. Phys. Phys. Chim. Biol. 1972, 11-12, 1711

(65) Salud, J.; Barrio, M.; López, D. O.; Tamarit, J. Ll.; Alcobé, X. J. Appl. Crystallogr. 1998, 31, 748.

(66) Weigel, D.; Beguemsi, T.; Garnier, P.; Gerad, J. F. J. Solid State Chem. 1978, 23, 241 